\title{
Gestational exposure to volatile organic compounds (VOCs) in Northeastern British Columbia, Canada: A pilot study
}

\author{
Élyse Caron-Beaudoin ${ }^{\mathrm{a}, \mathrm{b}, \mathrm{c}, \mathrm{d}, *,}$, Naomi Valter ${ }^{\mathrm{a}, \mathrm{b}}$, Jonathan Chevrier ${ }^{\mathrm{e}}$, Pierre Ayotte $^{\mathrm{f}, \mathrm{g}}$, \\ Katherine Frohlich ${ }^{\mathrm{b}, \mathrm{h}}$, Marc-André Verner ${ }^{\mathrm{a}, \mathrm{b}}$ \\ a Department of Occupational and Environmental Health, School of Public Health, Université de Montréal, 2375 chemin de la Cote-Sainte-Catherine, Montreal, QC H3T \\ 1A8, Canada \\ b Université de Montréal Public Health Research Institute (IRSPUM), Université de Montréal, 7101, Parc Ave., Montreal, QC H3N 1X7, Canada \\ c INRS-Institut Armand-Frappier, Université du Québec, 531 boulevard des Prairies, Laval, QC H7V 1B7, Canada \\ d Center for Interdisciplinary Research on Well-Being, Health, Society and Environment (CINBIOSE), Université du Québec à Montréal, C.P. 8888, Succursale Centre-ville, \\ Montreal, QC H3C 3P8, Canada \\ e Department of Epidemiology, Biostatistics and Occupational Health, McGill University Faculty of Medecine, 1020 Pine Avenue West, room 42, Montreal, QC H3A 1A2, \\ Canada \\ ${ }^{\mathrm{f}}$ Centre de toxicologie du Québec, Institut National de la Santé Publique du Québec, 945 avenue Wolfe, Québec, QC G1V 5B3, Canada \\ ${ }^{g}$ Axe Santé des Populations et Pratiques Optimales en Santé, Centre de Recherche du CHU de Québec-Université Laval, Hôpital du Saint-Sacrement, 1050 Chemin Ste-Foy, \\ Québec, QC G1S 4L8, Canada \\ ${ }^{\text {h }}$ Department of Social and Preventive Medicine, School of Public Health, Université de Montréal, 7101 Av du Parc, Montréal, QC H3N 1X9, Canada
}

\begin{abstract}
A B S T R A C T
Background: Northeastern British Columbia (Canada) is an area of intense hydraulic fracturing for unconventional natural gas exploitation. There have been multiple reports of air and water contamination by volatile organic compounds in the vicinity of gas wells. Although these chemicals are known developmental toxicants, no biomonitoring effort has been carried out in the region.

Objective: To evaluate gestational exposure to benzene and toluene in the Peace River Valley, Northeastern British Columbia (Canada).

Methods: Urine samples were collected over five consecutive days from 29 pregnant women. Metabolites of benzene ( $s$-phenylmercapturic acid (S-PMA) and trans, trans-muconic acid (t,t-MA)) and toluene (s-benzylmercapturic acid (S-BMA)) were measured in pooled urine samples from each participant. Levels of benzene metabolites were compared to those from the general Canadian population and from a biomonitoring study of residents from an area of active gas exploitation in Pavillion, Wyoming (USA). Levels measured in participants from the two recruitment sites, and self-identifying as Indigenous or non-Indigenous, were also compared. Results: Whereas the median S-PMA level $(0.18 \mu \mathrm{g} / \mathrm{g}$ creatinine) in our study was similar to that in the general Canadian population, the median t,t-MA level $(180 \mu \mathrm{g} / \mathrm{g}$ creatinine) was approximately 3.5 times higher. Five women had t,t-MA levels above the biological exposure index ${ }^{\circledast}$ proposed by the American Conference of Governmental Industrial Hygienists. The median urinary S-BMA level in our pilot study was $7.00 \mu \mathrm{g} / \mathrm{g}$ creatinine. Urinary metabolite levels were slightly higher in self-identifying Indigenous women, but this difference was only statistically significant for S-PMA.

Discussion: Urinary t,t-MA levels, but not S-PMA levels, measured in our study are suggestive of a higher benzene exposure in participating pregnant women from the Peace River Valley than in the general Canadian population. Given the small sample size and limitations of t,t-MA measurements (e.g., non-specificity), more extensive monitoring is warranted.
\end{abstract}

\section{Introduction}

Northeastern British Columbia (Canada) sits on the Montney Formation, a major source of natural gas. The Peace River Valley, located in Northeastern British Columbia, is an area of intense hydraulic fracturing (fracking) for unconventional natural gas exploitation. Indeed, $>28,000$ wells of unconventional natural gas have been drilled so far in this region (Adams et al., 2016). Some communities like

\footnotetext{
* Corresponding author.

E-mail address: elyse.caron-beaudoin@umontreal.ca (É. Caron-Beaudoin).
} 
Fort St-John are surrounded by $>400$ active wells (Northern Health, 2007).

Communities living in the vicinity of such development have raised concerns regarding the environmental impacts and potential health effects of unconventional natural gas exploitation. Water contamination in communities near unconventional natural gas exploitation has been previously described (Alawattegama et al., 2015; Llewellyn et al., 2015; Osborn et al., 2011). In the Peace River Valley, surface and groundwater quality has steadily decreased since the natural gas boom (GWSolutions, 2016). Moreover, studies have shown that air quality can be affected by intense fracking activities (Colborn et al., 2014; Rahm, 2011; Vinciguerra et al., 2015).

A myriad of contaminants are released during fracking operations, including volatile organic compounds such as benzene (Crowe et al., 2016; Gilman et al., 2013; Macey et al., 2014; Vengosh et al., 2014), a known human carcinogen (IARC, 2012). Effects of benzene on human health, including on fetal development, have been widely studied. Prenatal exposure to low environmental levels of benzene or a mixture of organic solvents has been associated with reduced birth weight (Aguilera et al., 2009; Chen et al., 2000; Ha et al., 2002; Slama et al., 2009; Zahran et al., 2012), increased risk of childhood leukemia (Carlos-Wallace et al., 2016; Whitworth et al., 2008; Zhou et al., 2014) and birth defects such as cleft palate and spina bifida (Lupo et al., 2011; Tanner et al., 2015). In utero exposure to high concentrations of toluene was also associated with growth retardation, preterm birth (Wilkinshaug and Gabow, 1991), spontaneous abortion and reduced fertility (Bukowski, 2001). In other regions of unconventional natural gas exploitation, recent studies found associations between density and proximity of hydraulic fracturing wells and prevalence of birth defects as well as low birth weights (Hill, 2012; McKenzie et al., 2014). Finally, a recent study determined that 95 out of 240 chemicals (with toxicity information) present in hydraulic fracturing fluids are developmental toxicants (Elliott et al., 2016).

Because of their particular physiological state and the ongoing development of several physiological systems, pregnant women and their developing fetuses are particularly vulnerable to toxic insults. Furthermore, Indigenous communities which represent $12 \%$ of the Northeast British Columbia population (Foster et al., 2011), experience health and social inequities due to land dispossession and inadequate provision of health, social and education services (Frohlich et al., 2006; Reading and Wien, 2009). It has been suggested that exposure to environmental chemicals in socioeconomically disadvantaged children contributes to health inequities (Miranda et al., 2009).

In this pilot study we aimed to evaluate exposure to volatile organic compounds in 30 pregnant women from the Peace River Valley, Northeastern British Columbia (Canada) and to compare exposure levels with those measured in: 1) women from the general Canadian population (Canadian Health Measures Survey (CHMS)) and; 2) residents of an area of active gas exploitation in Pavillion, Wyoming (USA).

\section{Material and methods}

\subsection{Study area and recruitment}

We developed partnerships with two medical clinics located in Chetwynd and Dawson Creek (British Columbia, Canada), and pregnant women were recruited from September to November 2016 during their prenatal follow-up following approval from the physician or nurse practitioner. Chetwynd and Dawson Creek are located at $100 \mathrm{~km}$ from each other in the Peace River Valley, a region of intense unconventional natural gas extraction. Both communities are surrounded by between 10 and 150 active natural gas wells, at least (Northern Health, 2007) (Fig. 1). While Chetwynd is surrounded by less active wells, it is located near the Pine River Gas Plant. Medical clinics located in these cities are among the few clinics offering pregnancy follow-ups in this region.
Eligible participants ( $>18$ years of age, English-Speaking) were met privately, given information on the research project, and had the opportunity to ask questions. Women who agreed to participate signed a consent form and filled out a questionnaire on sociodemographic and physiologic parameters, diet, smoking habits and drinking water source. This study was approved by the Northern Health Research Review Committee and by the Université de Montréal Institutional Review Board.

\subsection{Sampling and chemical analyses}

Participants were asked to collect $12 \mathrm{~mL}$ urine samples over five consecutive days. This sampling method accounts for variability in dayto-day exposure and diet. The samples were retrieved directly at the participants' home, and were kept in the freezer at $-20{ }^{\circ} \mathrm{C}$ until transported on dry ice to the Université de Montréal. For each participant, $1 \mathrm{~mL}$ of each of the five urine samples were pooled into a single $5 \mathrm{~mL}$ sample that was subsequently analyzed for two benzene metabolites (s-phenylmercapturic acid (S-PMA) and trans,trans muconic acid (t,t-MA)) and one toluene metabolite (s-benzylmercapturic acid (SBMA)). Metabolites were extracted from urine on a solid phase extraction plate using a Perkin Elmer Janus Automated Workstation. Extracts were dried, taken up in mobile phase and analyzed by Ultra Performance Liquid Chromatography (UPLC) coupled to tandem mass spectrometry at the Centre de toxicologie du Québec laboratory in Quebec City, Canada (INSPQ, 2009). Limits of detection were $0.08 \mu \mathrm{g} / \mathrm{L}$ for S-PMA, $0.8 \mu \mathrm{g} / \mathrm{L}$ for t,t-MA and $0.07 \mu \mathrm{g} / \mathrm{L}$ for S-BMA. Creatinine was measured using the colorimetric end-point Jaffe method (INSPQ, 2008).

\subsection{Statistical analyses}

Urinary levels of volatile organic compound metabolites measured in participants from the regions of Dawson Creek and Chetwynd, and self-identifying as Indigenous or non-Indigenous, were compared using the non-parametric Mann-Whitney $U$ test. The relationship between the levels of the two benzene metabolites (S-PMA and t,t-MA) was evaluated using Spearman's rank correlation analyses. All analyses were performed using IBM SPSS Statistics for Windows, Version 22.0 (IBM Corp., Armonk, NY).

\section{Results}

A total of 30 pregnant women were recruited for this pilot study, and 29 participants completed the sampling process (one participant had a miscarriage). The median sampling time was 9:00 PM, and ranged from 2:00 PM (10th percentile) to 11:00 PM (95th percentile). $50 \%$ of the participants were recruited at the Chetwynd medical clinic, and $50 \%$ at the Dawson Creek clinic. $43.3 \%$ of participants self-identified as Indigenous. $93.3 \%$ of participants had at least a high school diploma, and $20 \%$ of them worked in the industrial sector. Two participants reported smoking at the time of recruitment, and four reported being exposed to second-hand smoke during their pregnancy. Tap water was the main drinking water source for $70 \%$ of the participants (Table 1).

Participants that reported exposure to cigarette smoke $(n=12$; smoking at least 100 cigarettes in their whole life $(n=7)$, being active smokers at the time of recruitment $(n=2)$ or exposed to second-hand smoke $(n=4)$ had median urinary S-PMA, t,t-MA and S-BMA levels of $0.21,202$ and $6.88 \mu \mathrm{g} / \mathrm{g}$ creatinine, respectively. Participants that reported working in an industrial field $(n=6)$ such as mining industry, natural gas, construction, forestry, pipeline maintenance or at hydroelectric dams, had median urinary S-PMA, t,t-MA and S-BMA levels of $0.23,347$ and $4.31 \mu \mathrm{g} / \mathrm{g}$ creatinine, respectively. Maximum urinary levels of S-PMA, t,t-MA and S-BMA were 1.92, 1182 and $100 \mu \mathrm{g} / \mathrm{g}$ creatinine, respectively.

Median urinary levels of S-PMA, t,t-MA and S-BMA in participants 

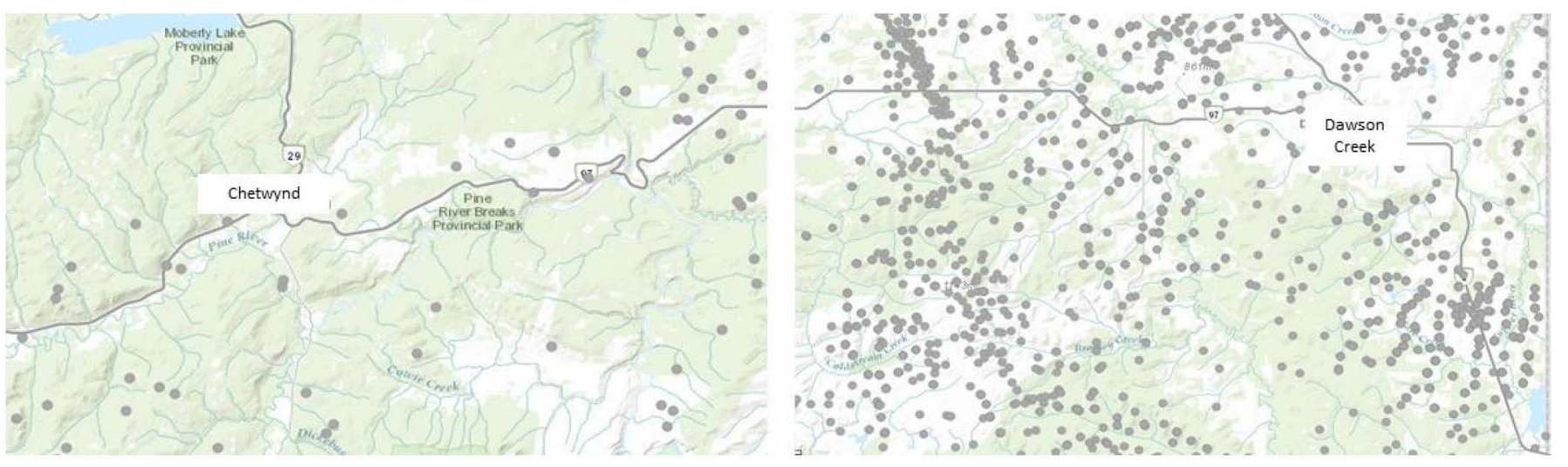

Fig. 1. Map of Chetwynd and Dawson Creek areas with hydraulic fracturing wells (circles) in 2007 (Open Data from BC Oil and Gas Commission).

with a household income less than $\$ 20,000 /$ year were of $0.41,319$ and $7.21 \mu \mathrm{g} / \mathrm{g}$ creatinine, respectively. Participants reporting a household income between $\$ 50,000$ and $\$ 100,000$ /year had median urinary levels of S-PMA, t,t-MA and S-BMA of $0.19,182$ and $5.60 \mu \mathrm{g} / \mathrm{g}$ creatinine, respectively, while median levels in participants with annual household income over $\$ 100,000 /$ year were $0.17,171$ and $9.7 \mu \mathrm{g} / \mathrm{g}$ creatinine. SPMA median urinary levels were statistically higher in participants with annual income less than $\$ 20,000(p=0.036)$.

All metabolite levels were above the limits of detection. Sociodemographic characteristics were similar across regions and Indigenous/non-Indigenous status. Overall, median S-PMA concentrations in our pilot study were similar to those found in the general Canadian population (Table 2), and median S-PMA levels in pregnant women recruited in Chetwynd $(0.20 \mu \mathrm{g} / \mathrm{g}$ creatinine) and Dawson Creek ( $0.18 \mu \mathrm{g} / \mathrm{g}$ creatinine) were not statistically different (Fig. 2).

The median S-PMA level in Indigenous women $(0.24 \mu \mathrm{g} / \mathrm{g}$ creatinine) was higher than in Non-Indigenous women $(0.14 \mu \mathrm{g} / \mathrm{g}$ creatinine $)$ $(p=0.017)$ (Fig. 3). More precisely, Indigenous $(n=9)$ and Non-Indigenous women $(n=5)$ living in the Chetwynd area had median urinary S-PMA levels of 0.24 and $0.10 \mu \mathrm{g} / \mathrm{g}$ creatinine, respectively. Indigenous $(n=4)$ and Non-Indigenous participants $(n=11)$ from the Dawson Creek area had median urinary S-PMA levels of 0.50 and $0.15 \mu \mathrm{g} / \mathrm{g}$ creatinine, respectively.

The median t,t-MA levels in pregnant women recruited in Chetwynd

- - - S-PMA levels in general Canadian population $(0.14 \mu \mathrm{g} / \mathrm{g}$ creatinine $)$

- Individual S-PMA levels ( $\mu \mathrm{g} / \mathrm{g}$ creatinine)

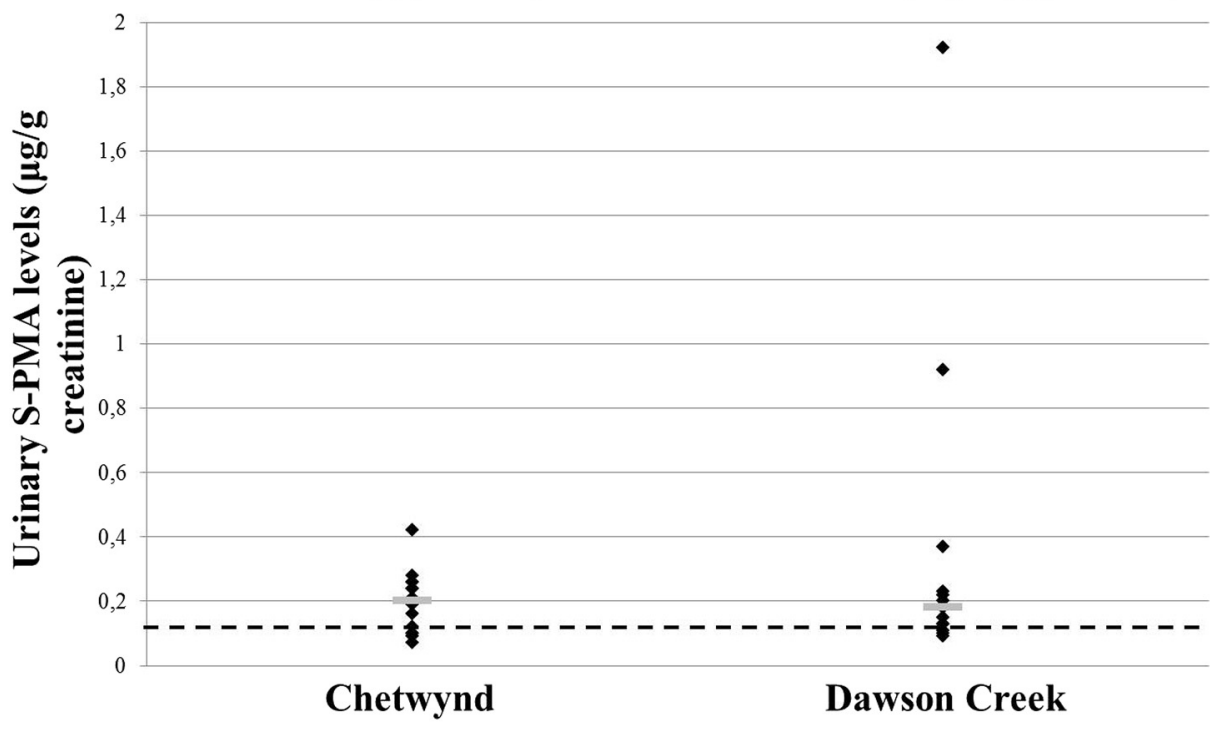

( $271 \mu \mathrm{g} / \mathrm{g}$ creatinine) was 1.6 fold higher than in pregnant women recruited in Dawson Creek (171 $\mu \mathrm{g} / \mathrm{g}$ creatinine), but this difference did not reach statistical significance $(p=0.09)$. Respectively, pregnant women from Chetwynd and Dawson had median t,t-MA levels 5.3 and 3.4 times higher than women from the general Canadian population. Moreover, 5 women out of 29 had t,t-MA levels higher than the biological exposure index $\left(\mathrm{BEI}^{\oplus}\right)$ of $500 \mu \mathrm{g} / \mathrm{g}$ creatinine proposed by the American Conference of Governmental Industrial Hygienists (ACGIH) (ACGIH, 2012) (Fig. 4).

The median t,t-MA level in Indigenous women ( $319 \mu \mathrm{g} / \mathrm{g}$ creatinine) was higher than in Non-Indigenous women $(142 \mu \mathrm{g} / \mathrm{g}$ creatinine), although this difference was not statistically significant $(p=0.07)$ (Fig. 5). This difference was more striking when comparing the median $\mathrm{t}, \mathrm{t}$,-MA levels by ethnicity and region of residence. Indigenous women living in the Chetwynd and Dawson Creek areas had median t,t-MA levels of $319 \mu \mathrm{g} / \mathrm{g}$ creatinine and $251 \mu \mathrm{g} / \mathrm{g}$ creatinine, respectively. Median t,t-MA levels were approximately 4 and 2 times lower in NonIndigenous women from Chetwynd (85.7 $\mu \mathrm{g} / \mathrm{g}$ creatinine) and Dawson Creek (146 $\mu \mathrm{g} / \mathrm{g}$ creatinine).
Fig. 2. Individual and median urinary levels of $S$-phenylmercapturic acid (S-PMA) ( $\mu \mathrm{g} / \mathrm{g}$ creatinine) in our pilot study, by region. Five urine samples were obtained from each participant over five consecutive days. These urine samples were pooled prior to chemical analysis. The dotted line represents the S-PMA median level in the general Canadian population (as measured in the CHMS cycle 3). 


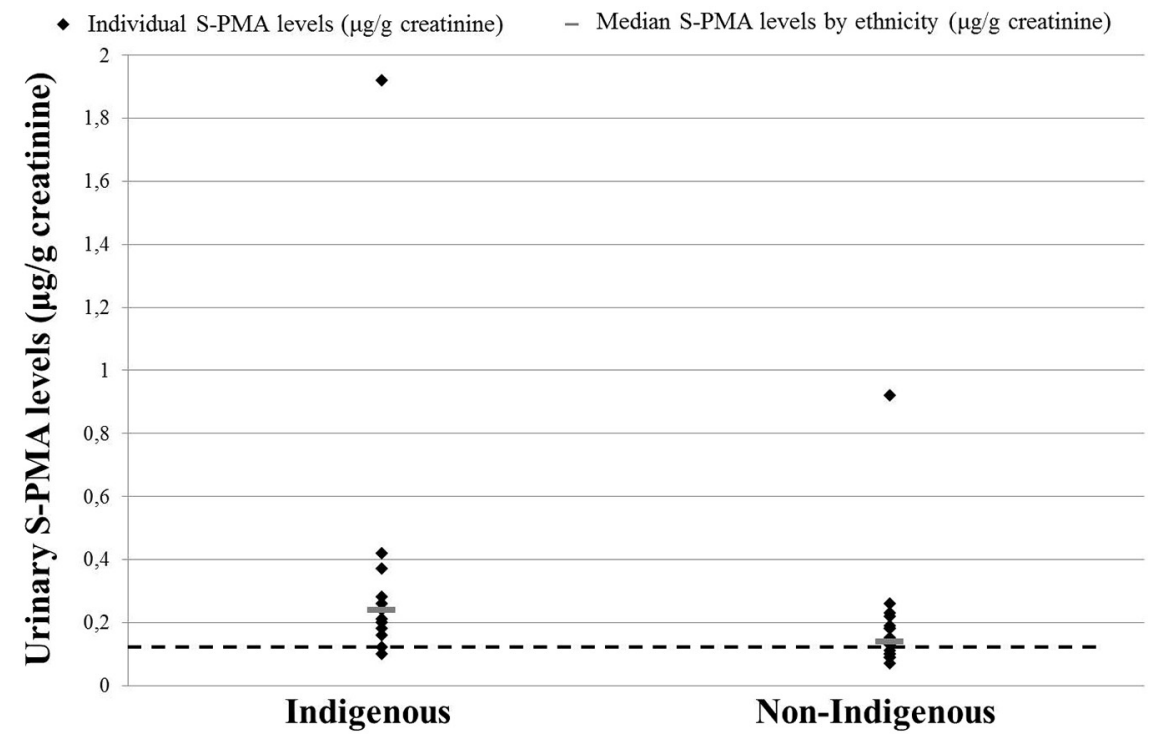

Fig. 3. Individual and median urinary levels of $S$-phenylmercapturic acid (S-PMA) ( $\mu \mathrm{g} / \mathrm{g}$ creatinine) in our pilot study, by ethnicity. Five urine samples were obtained from each participant over five consecutive days. These urine samples were pooled prior to chemical analysis. The dotted line represents the S-PMA median level in the general Canadian population (as measured in the CHMS cycle 3).

\section{Discussion}

\subsection{Comparison with the general Canadian population}

In this pilot study we analyzed two benzene metabolites (S-PMA and t,t,-MA) and one toluene metabolite (S-BMA) in urine samples of pregnant women living in Northeastern British Columbia. In 2012, the median urinary level of S-BMA in females from the general American population that participated in the National Health and Nutrition Examination Survey (NHANES) was $7.2 \mu \mathrm{g} / \mathrm{g}$ creatinine (CDC, 2015). A study conducted by Schettgen et al. (2008) measured toluene metabolite S-BMA in urine of 30 participants from the German general population. In non-smokers and smokers, median urinary S-BMA levels were $8.2 \mu \mathrm{g} / \mathrm{L}$ and $11.5 \mu \mathrm{g} / \mathrm{L}$, respectively. We reported a similar median urinary S-BMA level of $8.6 \mu \mathrm{g} / \mathrm{L}$ in this pilot study. Urinary S-PMA levels were similar to those from women who participated in the Canadian Health Measure Survey (CHMS). However, the median urinary t,t,MA level $(180 \mu \mathrm{g} / \mathrm{g}$ creatinine) was approximately 3.5 times higher in our pilot study compared to that from CHMS ( $51 \mu \mathrm{g} / \mathrm{g}$ creatinine) (Health Canada, 2015). Moreover, 8 participating women out of 29
(28\%) showed t,t,-MA levels above the 95th percentile measured in the CHMS $(460 \mu \mathrm{g} / \mathrm{g}$ creatinine) (Health Canada, 2015). In Pavillion (Wyoming, USA), a region of intense hydraulic fracturing activity, Crowe et al. (2016) also reported elevated benzene concentrations in ambient air near residences located close to well pads (between 8.7 and $780 \mathrm{ppb}$ ) and higher median urinary t,t-MA level in residents close to hydraulic fracturing wells $(369 \mu \mathrm{g} / \mathrm{g}$ creatinine), compared to the general American population $(76.9 \mu \mathrm{g} / \mathrm{g}$ creatinine).

\subsection{Sources of benzene in Northeastern British Columbia}

Benzene exposure can occur from active and passive smoking, filling gas tanks and automobile driving (Wallace, 1990). Benzene in products such as paints and adhesives can contribute to exposure, but concentrations in these materials are relatively low (Wallace, 1990). A potential benzene exposure source in our group of pregnant women might include the intense fracking activity in the region. In Northeastern British Columbia around 28,000 wells were drilled to extract natural gas (Adams et al., 2016). Natural gas' main constituent is methane, but it also contains other chemicals including benzene (Hendler

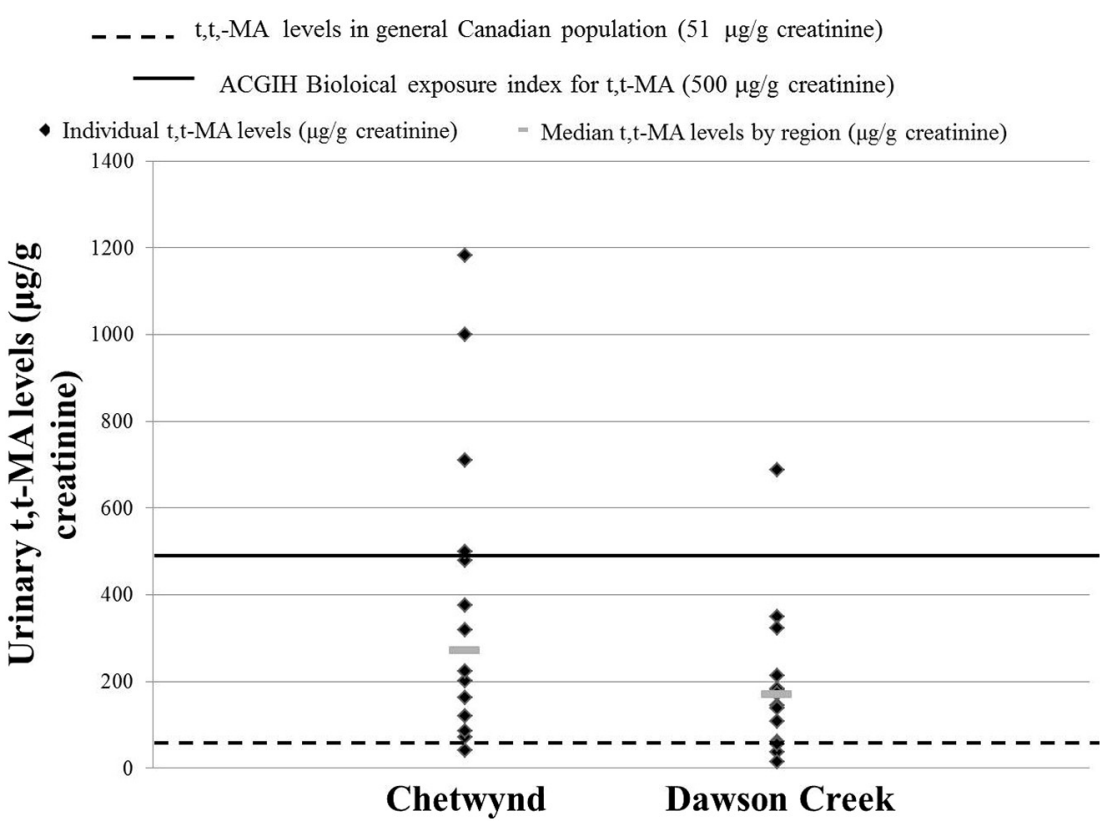

Fig. 4. Individual and median urinary levels of trans,trans muconic acid (t,t-MA) ( $\mu \mathrm{g} / \mathrm{g}$ creatinine) in our pilot study, by region. Five urine samples were obtained from each participant over five consecutive days. These urine samples were pooled prior to chemical analysis. The dotted line represents the median t,t,-MA level in the general Canadian population (as measured in the CHMS cycle 3). The bold black line represents the biological exposure index $\left(\mathrm{BEI}^{\circledR}\right)$ of $500 \mu \mathrm{g} / \mathrm{g}$ creatinine for urinary t,t-MA levels adopted by the ACGIH. 


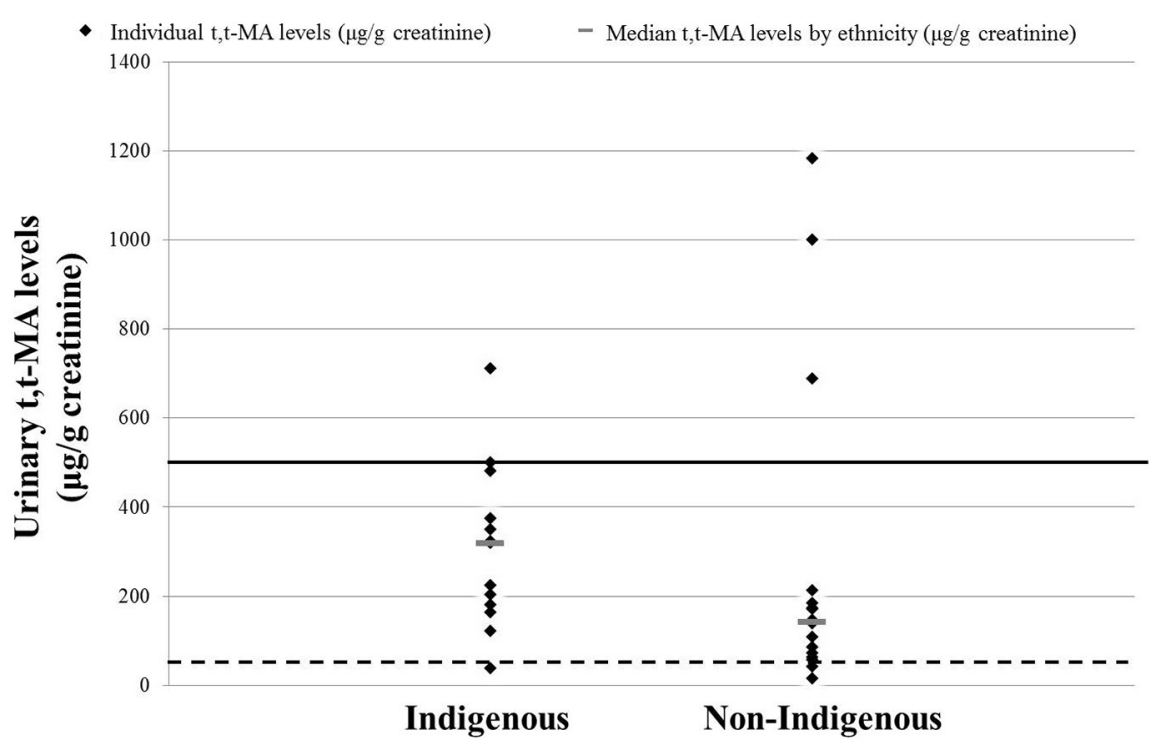

Fig. 5. Individual and median urinary levels of trans,trans muconic acid (t,t-MA) ( $\mu \mathrm{g} / \mathrm{g}$ creatinine) in our pilot study, by ethnicity. Five urine samples were obtained from each participant over five consecutive days. These urine samples were pooled prior to chemical analysis. The dotted line represents the median t,t,-MA level in the general Canadian population (as measured in the CHMS cycle 3 ). The bold black line represents the biological exposure index $\left(\mathrm{BEI}^{\circledast}\right)$ of $500 \mu \mathrm{g} / \mathrm{g}$ creatinine for urinary $t, t-M A$ levels adopted by the ACGIH.
Table 1

Characteristics of pregnant women from Dawson Creek and Chetwynd, BC $(n=30)$.

\begin{tabular}{|c|c|c|}
\hline Characteristic & n (\%) & Median (range) \\
\hline Age (years) & & $31(21-41)$ \\
\hline \multicolumn{3}{|l|}{ Region of residence } \\
\hline Chetwynd & $15(50.0)$ & \\
\hline Dawson Creek & $15(50.0)$ & \\
\hline \multicolumn{3}{|l|}{ Self-identify as Indigenous } \\
\hline Yes & $13(43.3)$ & \\
\hline No & $17(56.7)$ & \\
\hline \multicolumn{3}{|l|}{ Highest education degree obtained } \\
\hline High school unfinished & $2(6.7)$ & \\
\hline High school diploma & $8(26.7)$ & \\
\hline Certificate, diploma or associate degree & $10(33.3)$ & \\
\hline University degree (Bachelor, Master, Doctorate) & $10(33.3)$ & \\
\hline \multicolumn{3}{|l|}{ Participants working in industrial field } \\
\hline Yes & $6(20)$ & \\
\hline No & $24(80)$ & \\
\hline \multicolumn{3}{|l|}{ Smoker at time of recruitment } \\
\hline Yes & $2(6.7)$ & \\
\hline No & $28(93.3)$ & \\
\hline \multicolumn{3}{|l|}{ Second-hand smoke during pregnancy } \\
\hline Yes & $4(13.3)$ & \\
\hline No & $26(86.7)$ & \\
\hline Gestational age (weeks) & & $18.5(6.0-39.0)$ \\
\hline \multicolumn{3}{|l|}{ Drinking water source } \\
\hline Tap water & $21(70.0)$ & \\
\hline Bottled water & $8(26.7)$ & \\
\hline Other & $1(3.3)$ & \\
\hline Pre-pregnancy BMI & & $23.9(19.1-36.3)$ \\
\hline$<24.9$ & 17 (56.7) & \\
\hline $25.0-29.9$ & $4(13.3)$ & \\
\hline $30.0-34.9$ & $3(10.0)$ & \\
\hline $35.0-39.9$ & $2(6.7)$ & \\
\hline
\end{tabular}

et al., 2009). It has been demonstrated that workers from the natural gas industry are exposed to volatile organic compounds such as benzene and toluene during well development and production (Hendler et al., 2009). Several studies conducted in the United States found that the oil and gas industry is an important source of benzene exposure, and systematically reported higher levels of organic volatile compounds in ambient air from these regions compared to regional samples (Adgate et al., 2014; Colborn et al., 2014; Gilman et al., 2013; Pétron et al., 2012; Zielinska et al., 2011). Moreover, fracking activities are a risk for water resources (Vengosh et al., 2014), and water contamination may be a potential pathway for benzene exposure. Indeed, it has been demonstrated that following surface spills from natural gas facilities in Colorado, elevated levels of benzene were detected in the groundwater system (Gross et al., 2013). In Pennsylvania, inadequate disposal of hydraulic fracturing wastewater contaminated surface waters with benzene, barium and radium (Ferrar et al., 2013; Warner et al., 2013).

In Northeastern British Columbia, the recent approval of the Liquefied Natural Gas Plants could lead to the drilling of 50,000 new hydraulic fracturing wells in the region (Hughes, 2014). Therefore, monitoring initiatives in human populations, air and water are needed.

\subsection{Environmental justice}

In our pilot study, the median urinary t,t-MA level in Indigenous women was 2.3 times higher than in Non-Indigenous women, although this difference was non statistically significant $(p=0.07)$ (Fig. 5). This difference in t,t-MA levels would need to be confirmed in a subsequent study with a larger sample size. Nonetheless, these preliminary results raise concerns regarding environmental racism which is "the intentional or unintentional racial discrimination in the enforcement of environmental rules and regulations, which leads to the singling-out of minority and low-income communities for the siting of noxious facilities" (Bullard, 2000). For instance, it has been demonstrated that hazardous waste facilities are disproportionately located in low income areas and communities of color (Bullard, 1983; Chavis and Lee, 1987; Gould, 1986; Mohai and Bryant, 1992; Norton et al., 2007; White, 1992). In Texas, Johnston et al. (2016) showed that the proportion of people of color living in the vicinity of hydraulic fracturing disposal wells was significantly higher than the proportion of non-Hispanic Whites. In Pennsylvania, a recent study showed that farmers with small operations face increased environmental risks from hydraulic fracturing activities (Malin and DeMaster, 2015). Environmental injustice is a great concern, especially for Indigenous communities already facing health inequalities. Close contact between Indigenous people and their environment through spiritual practices and traditional lifestyle may increase their exposure to contaminants from industrial activities (Hoover et al., 2012), and such disproportionate environmental burden has already been demonstrated in Canada (Mackenzie et al., 2005; Van Larebeke et al., 2008).

\subsection{Limitations}

Our pilot study has limitations, and therefore, caution should be exerted when interpreting biomarker levels in participating pregnant women from Northeastern British Columbia. First, the small number of participants prevents us from drawing conclusions on the sources of benzene and the potential need for exposure mitigation strategies. 
Table 2

Urinary levels of benzene and toluene metabolites in Dawson Creek and Chetwynd (BC), in the general Canadian population (CHMS), and in the Pavillion Wyoming Study.

\begin{tabular}{|c|c|c|c|}
\hline & \multicolumn{2}{|l|}{ Benzene metabolites } & \multirow{2}{*}{$\begin{array}{l}\text { Toluene metabolite } \\
\text { S-BMA ( } \mu \mathrm{g} / \mathrm{g} \text { creatinine) }\end{array}$} \\
\hline & S-PMA ( $\mu \mathrm{g} / \mathrm{g}$ creatinine) & t,t-MA ( $\mu \mathrm{g} / \mathrm{g}$ creatinine) & \\
\hline \multirow[t]{4}{*}{ Dawson Creek and Chetwynd, BC (this study) } & Median: 0.18 & Median: 180 & Median: 7.00 \\
\hline & 10th percentile: 0.09 & 10th percentile: 53.3 & 10th percentile: 3.1 \\
\hline & 95th percentile: 0.74 & 95th percentile: 899 & 95th percentile: 106.8 \\
\hline & $n=29$ & $n=29$ & $\mathrm{n}=29$ \\
\hline \multirow[t]{4}{*}{ CHMS cycle $3^{\text {a }}$} & Median: 0.14 & Median: 51.0 & Not measured \\
\hline & 10th percentile: < LOD & 10th percentile: 19.0 & \\
\hline & 95th percentile: 5.10 & 95th percentile: 460 & \\
\hline & $n=1248$ & $n=1260$ & \\
\hline \multirow[t]{2}{*}{ Pavillion, Wyoming study ${ }^{\mathrm{b}}$} & Median: < LOD & Median: 369 & Not measured \\
\hline & Maximum: 0.80 & Maximum: 2050 & \\
\hline
\end{tabular}

${ }^{\text {a }}$ Measured levels in females aged from 3 to 79 years old (Health Canada, 2015).

${ }^{\mathrm{b}}$ Only the median and maximum levels were available for the Pavillion, Wyoming study (Crowe et al., 2016).

Metabolic polymorphism could be a factor influencing urinary levels of benzene and toluene metabolites. A study conducted by Verdina et al. (2001) suggests that metabolic polymorphism affect the urinary levels of t,t-MA and S-PMA to a limited extent. Other factors to consider include the influence of sorbic acid on t,t-MA levels, exposure to cigarette smoke, and variations in urinary creatinine during pregnancy.

\subsubsection{Interference with sorbic acid}

Urinary t,t-MA levels can be influenced by factors other than benzene exposure, including the intake of sorbic acid, a food preservative partially metabolized into t,t-MA. Estimates of the intake of sorbic acid are in the range of $1-2 \mathrm{mg} / \mathrm{kg} /$ day $(60-120 \mathrm{mg} /$ day for a $60 \mathrm{~kg}$ woman), which results in an average of $78-114 \mu \mathrm{g} / \mathrm{g}$ creatinine of urinary t,t-MA levels (Mischek and Krapfenbauer-Cermak, 2012; Pezzagno and Maestri, 1997). To reach an average urinary t,t-MA level above $500 \mu \mathrm{g} / \mathrm{g}$ creatinine in pooled samples solely based on sorbic acid intake, large doses of sorbic acid would need to be ingested in the hours preceding urine sampling. We cannot rule out the possibility of higher sorbic acid consumption in participating pregnant women from the Peace River Valley compared to women included in CHMS.

\subsubsection{Smoking and second hand smoke}

It is well established that t,t-MA levels are influenced by smoking and second hand smoke exposure. Active and passive smoking were evaluated in the questionnaire and only four participants (13\%) reported smoking or being exposed to second hand smoke (Table 1). These participants did not exhibit urinary t,t-MA levels above the $500 \mu \mathrm{g} / \mathrm{g}$ creatinine biological exposure indices. It should be noted that this guideline is used in the context of industrial hygiene and may not be appropriate to evaluate risks for the general population, especially pregnant women that are in a more vulnerable physiological state. Only two participants $(7 \%)$ were smokers at the time of recruitment, compared to $11 \%$ in CHMS; the difference in t,t-MA levels between our pilot study and CHMS is therefore unlikely to be due to smoking.

\subsubsection{Creatinine adjustment during pregnancy}

Another factor that was taken into consideration is the creatinine levels that might change during pregnancy. These changes in creatinine levels could influence t,t-MA levels expressed in $\mu \mathrm{g} / \mathrm{g}$ creatinine, and consequently bias our comparisons with levels from CHMS. However, Melikian et al. (1994) compared urinary t,t-MA levels expressed in $\mu \mathrm{g} / \mathrm{g}$ creatinine in non-pregnant and pregnant non-smokers and found no significant differences. In addition, the median urinary t,t-MA level from our study in $\mu \mathrm{g} / \mathrm{L}(190 \mu \mathrm{g} / \mathrm{L})$ was also higher than that from CHMS $(46 \mu \mathrm{g} / \mathrm{L})$. These findings suggest that differences in urinary t,t-MA levels between our study and CHMS are probably not due to variations in urinary creatinine levels.

\subsection{Correlation between S-PMA and t,t-MA}

To ensure that the use of t,t-MA as an indicator of potentially higher benzene exposure is adequate, we tested the strength of the correlation between urinary S-PMA and t,t-MA levels $(\mu \mathrm{g} / \mathrm{L})$ using Spearman rank correlation. A moderate, statistically-significant correlation was found $(r=0.47)$. Other studies also reported similar correlation coefficients between the same urinary metabolites in environmentally exposed adults (Melikian et al., 1999) and in children (Fang et al., 2000). A number of studies also positively evaluated the accuracy of using urinary t,t-MA as a biomarker of benzene exposure at environmental and mostly occupational levels (Cocco et al., 2003; Hoet et al., 2009; Scherer et al., 1998). Finally, studies of occupational and environmental exposures showed correlations between benzene concentration in air and urinary t,t-MA levels (Ducos et al., 1992; Inoue et al., 1989; Kang et al., 2005; Lovreglio et al., 2010). Urinary levels of benzene and other volatile organic compounds have proven to be excellent markers for environmental exposure (Fustinoni et al., 2010; Tsangari et al., 2017; Waidyanatha et al., 2001) and should be considered in future research efforts.

\section{Conclusion}

Results from our pilot study, although limited because of the small sample size and limitations related to our exposure biomarker (e.g., non-specificity), are suggestive of a potential higher benzene exposure in participating pregnant women than in the general Canadian population. Whether the high urinary t,t-MA levels measured in this study are related to hydraulic fracking remains unknown. Given the documented health effects of benzene, especially those occurring through in utero exposure, and the growing hydraulic fracturing industry in this region, this first biomonitoring initiative certainly highlights the need of further research to better delineate associated health risks.

\section{Acknowledgements}

This research project was funded through a new initiative grant program from the Université de Montréal Public Health Research Institute (IRSPUM), and the West Moberly First Nations. We thank all the participants, as well as the Treaty 8 Tribal Association, the Saulteau First Nations and the West Moberly First Nations for their support and welcome on their traditional territory. We also thank the staff from the medical clinics for their assistance during the recruitment process.

\section{References}

ACGIH, 2012. Appendix B: Biological Exposure Guidelines (ACGIH BEI and OSHA 
Expanded Standards Only).

Adams, C., Janicki, E., Balogun, A., 2016. Summary of shale gas activity in Northeast British Columbia 2013. In: Oil and Gas Reports 2016. British Columbia Ministry of Natural Gas Development, pp. 1-39.

Adgate, J.L., Goldstein, B.D., McKenzie, L.M., 2014. Potential public health hazards, exposures and health effects from unconventional natural gas development. Environ. Sci. Technol. 48, 8307-8320.

Aguilera, I., Guxens, M., Garcia-Esteban, R., Corbella, T., Nieuwenhuijsen, M.J., Foradada, C.M., Sunyer, J., 2009. Association between GIS-based exposure to urban air pollution during pregnancy and birth weight in the INMA Sabadell cohort. Environ. Health Perspect. 117, 1322.

Alawattegama, S.K., Kondratyuk, T., Krynock, R., Bricker, M., Rutter, J.K., Bain, D.J., Stolz, J.F., 2015. Well water contamination in a rural community in southwestern Pennsylvania near unconventional shale gas extraction. J. Environ. Sci. Health A 50, 516-528.

Bukowski, J.A., 2001. Review of the epidemiological evidence relating toluene to reproductive outcomes. Regul. Toxicol. Pharmacol. 33, 147-156.

Bullard, R.D., 1983. Solid waste sites and the black Houston community. Sociol. Inq. 53, 273-288.

Bullard, R.D., 2000. Dumping in Dixie: Race, Class, and Environmental Quality ed^eds. Westview Press Boulder, CO.

Carlos-Wallace, F.M., Zhang, L., Smith, M.T., Rader, G., Steinmaus, C., 2016. Parental, in utero, and early-life exposure to benzene and the risk of childhood leukemia: a metaanalysis. Am. J. Epidemiol. 183, 1-14.

CDC, 2015. C.f.D.C.a.P. National Health and Nutrition Examination Survey Data. Hyattsville, MD: U.S. Department of Health and Human Services, Centers for Disease Control and Prevention.

Chavis, B., Lee, C., 1987. Toxic Wastes and Race in the United States: A National Report on the Racial and Socio-Economic Characteristics of Communities with Hazardous Waste Sites Ed^Eds. Comission for Racial Justice, United Church of Christ, New York.

Chen, D., Cho, S.-I., Chen, C., Wang, X., Damokosh, A.I., Ryan, L., Smith, T.J., Christiani, D.C., Xu, X., 2000. Exposure to benzene, occupational stress, and reduced birth weight. Occup. Environ. Med. 57, 661-667.

Cocco, P., Tocco, M.G., Ibba, A., Scano, L., Ennas, M.G., Flore, C., Randaccio, F.S., 2003. Trans, trans-Muconic acid excretion in relation to environmental exposure to benzene. Int. Arch. Occup. Environ. Health 76, 456-460.

Colborn, T., Schultz, K., Herrick, L., Kwiatkowski, C., 2014. An exploratory study of air quality near natural gas operations. Hum. Ecol. Risk Assess. 20, 86-105.

Crowe, E., Patton, S., Thomas, D., Thorpe, B., 2016. When the Wind Blows: Tracking Toxic Chemicals in Gas Fields and Impacted Communities Battleboro. VT, Coming Clean.

Ducos, P., Gaudin, R., Bel, J., Maire, C., Francin, J., Robert, A., Wild, P., 1992. Trans, trans-Muconic acid, a reliable biological indicator for the detection of individual benzene exposure down to the ppm level. Int. Arch. Occup. Environ. Health 64, 309-313.

Elliott, E.G., Ettinger, A.S., Leaderer, B.P., Bracken, M.B., Deziel, N.C., 2016. A systematic evaluation of chemicals in hydraulic-fracturing fluids and wastewater for reproductive and developmental toxicity. J. Expos. Sci. Environ. Epidemiol. 27 (1), 90-99.

Fang, M.Z., Shin, M.K., Park, K.W., Kim, Y.S., Lee, J.W., Cho, M.H., 2000. Analysis of urinary S-phenylmercapturic acid and trans, trans-muconic acid as exposure biomarkers of benzene in petrochemical and industrial areas of Korea. Scand. J. Work Environ. Health 62-66.

Ferrar, K.J., Michanowicz, D.R., Christen, C.L., Mulcahy, N., Malone, S.L., Sharma, R.K., 2013. Assessment of effluent contaminants from three facilities discharging Marcellus Shale wastewater to surface waters in Pennsylvania. Environ. Sci. Technol. 47, 3472-3481.

Foster, L.T., Keller, C.P., McKee, B., Ostry, A., 2011. British Columbia Atlas of Wellness 2nd Edition ed`eds. Western Geographical Press.

Frohlich, K.L., Ross, N., Richmond, C., 2006. Health disparities in Canada today: some evidence and a theoretical framework. Health Policy 79, 132-143.

Fustinoni, S., Rossella, F., Campo, L., Mercadante, R., Bertazzi, P.A., Urinary, B.T.E.X., 2010. MTBE and naphthalene as biomarkers to gain environmental exposure profiles of the general population. Sci. Total Environ. 408, 2840-2849.

Gilman, J.B., Lerner, B., Kuster, W., De Gouw, J., 2013. Source signature of volatile organic compounds from oil and natural gas operations in northeastern Colorado. Environ. Sci. Technol. 47, 1297-1305.

Gould, J.M., 1986. Quality of Life in American Neighborhoods. Levels of Affluence, Toxic Waste, and Cancer Mortality in Residential Zip Code Areas.

Gross, S.A., Avens, H.J., Banducci, A.M., Sahmel, J., Panko, J.M., Tvermoes, B.E., 2013. Analysis of BTEX groundwater concentrations from surface spills associated with hydraulic fracturing operations. J. Air Waste Manage. Assoc. 63, 424-432.

GWSolutions, 2016. Peace River Regional District Water Quality Database and Analysis. BC, Nanaimo.

Ha, E., Cho, S.-I., Chen, D., Chen, C., Ryan, L., Smith, T.J., Xu, X., Christiani, D.C., 2002. Parental exposure to organic solvents and reduced birth weight. Arch. Environ. Health 57, 207-214.

Health, Northern, 2007. Population Health and Oil and Gas Activities: A Preliminary Assessment of the Situation in North Eastern BC.

Health Canada, 2015. Third Report on Human Biomonitoring of Environmental Chemicals in Canada: Results of the Canadian Health Measures Survey Cycle 3 $(2012-2013)$

Hendler, A., Nunn, J., Lundeen, J., McKaskle, R., 2009. VOC emissions from oil and condensate storage tanks. Final report prepared for the Texas environmental research consortium. Available online at. http://filesharcedu/Projects/AirQuality/Projects/ H051C/H051CFinalReport.pdf, Accessed date: February 2013.
Hill, E.L., 2012. Unconventional Natural Gas Development and Infant Health: Evidence from Pennsylvania. Charles H Dyson School of Applied Economics and Management Working Paper. 12. pp. 2013.

Hoet, P., De Smedt, E., Ferrari, M., Imbriani, M., Maestri, L., Negri, S., De Wilde, P., Lison, D., Haufroid, V., 2009. Evaluation of urinary biomarkers of exposure to benzene: correlation with blood benzene and influence of confounding factors. Int. Arch. Occup. Environ. Health 82, 985-995.

Hoover, E., Cook, K., Plain, R., Sanchez, K., Waghiyi, V., Miller, P., Dufault, R., Sislin, C., Carpenter, D.O., 2012. Indigenous peoples of North America: environmental exposures and reproductive justice. Environ. Health Perspect. 120, 1645-1649.

Hughes, D., 2014. BC LNG A Reality Check Global Sustainability Research Inc.

IARC, I.A.f.R.o.C, 2012. Chemical Agents and Related Occupations: A Review of Human Carcinogens. Lyon, France.

Inoue, O., Seiji, K., Nakatsuka, H., Watanabe, T., Yin, S., Li, G., Cai, S., Jin, C., Ikeda, M., 1989. Urinary t, t-muconic acid as an indicator of exposure to benzene. Br. J. Ind. Med. 46, 122-127.

INSPQ, I.n.d.l.s.p.d.Q, 2008. Analytical Method for the Determination of Urine Creatinine on Hitachi 917 (C-530), Condensed Version. Laboratoire de toxicologie, Québec, QC.

INSPQ, I.n.d.l.s.p.d.Q, 2009. Analytical Method for the Determination of Benzene Metabolites in Urine by UPLC-MS-MS (E-460), Condensed Version for CHMS. Laboratoire de toxicologie, Québec, QC.

Johnston, J.E., Werder, E., Sebastian, D., 2016. Wastewater disposal wells, fracking, and environmental injustice in southern Texas. Am. J. Public Health 106, 550-556.

Kang, S.-K., Lee, M.-Y., Kim, T.-K., Lee, J.-O., Ahn, Y.S., 2005. Occupational exposure to benzene in South Korea. Chem. Biol. Interact. 153, 65-74.

Llewellyn, G.T., Dorman, F., Westland, J.L., Yoxtheimer, D., Grieve, P., Sowers, T., Humston-Fulmer, E., Brantley, S.L., 2015. Evaluating a groundwater supply contamination incident attributed to Marcellus Shale gas development. Proc. Natl. Acad. Sci. 112, 6325-6330.

Lovreglio, P., Barbieri, A., Carrieri, M., Sabatini, L., Fracasso, M.E., Doria, D., Drago, I., Basso, A., D'Errico, M.N., Bartolucci, G.B., 2010. Validity of new biomarkers of internal dose for use in the biological monitoring of occupational and environmental exposure to low concentrations of benzene and toluene. Int. Arch. Occup. Environ. Health 83, 341-356.

Lupo, P.J., Symanski, E., Waller, D.K., Chan, W., Langlois, P.H., Canfield, M.A., Mitchell, L.E., 2011. Maternal exposure to ambient levels of benzene and neural tube defects among offspring: Texas, 1999-2004. Environ. Health Perspect. 119, 397.

Macey, G.P., Breech, R., Chernaik, M., Cox, C., Larson, D., Thomas, D., Carpenter, D.O., 2014. Air concentrations of volatile compounds near oil and gas production: a community-based exploratory study. Environ. Health 13, 82.

Mackenzie, C.A., Lockridge, A., Keith, M., 2005. Declining sex ratio in a first nation community. Environ. Health Perspect. 1295-1298.

Malin, S.A., DeMaster, K.T., 2015. A devil's bargain: rural environmental injustices and hydraulic fracturing on Pennsylvania's farms. J. Rural. Stud. 47, 278-290.

McKenzie, L.M., Guo, R., Witter, R.Z., Savitz, D.A., Newman, L.S., Adgate, J.L., 2014. Birth outcomes and maternal residential proximity to natural gas development in rural Colorado. Environ. Health Perspect. 122, 412.

Melikian, A.A., Prahalad, A.K., Secker-Walker, R.H., 1994. Comparison of the levels of the urinary benzene metabolite trans, trans-muconic acid in smokers and nonsmokers, and the effects of pregnancy. Cancer Epidemiol. Prev. Biomark. 3, 239-244.

Melikian, A.A., O'Connor, R., Prahalad, A.K., Hu, P., Li, H., Kagan, M., Thompson, S., 1999. Determination of the urinary benzene metabolites S-phenylmercapturic acid and trans, trans-muconic acid by liquid chromatography-tandem mass spectrometry. Carcinogenesis 20, 719-726.

Miranda, M.L., Kim, D., Reiter, J., Galeano, M.A.O., Maxson, P., 2009. Environmental contributors to the achievement gap. Neurotoxicology 30, 1019-1024.

Mischek, D., Krapfenbauer-Cermak, C., 2012. Exposure assessment of food preservatives (sulphites, benzoic and sorbic acid) in Austria. Food Addit. Contam. A 29, 371-382.

Mohai, P., Bryant, B.I., 1992. Environmental Racism: Reviewing the Evidence.

Norton, J.M., Wing, S., Lipscomb, H.J., Kaufman, J.S., Marshall, S.W., Cravey, A.J., 2007. Race, wealth, and solid waste facilities in North Carolina. Environ. Health Perspect. 1344-1350.

Osborn, S.G., Vengosh, A., Warner, N.R., Jackson, R.B., 2011. Methane contamination of drinking water accompanying gas-well drilling and hydraulic fracturing. Proc. Natl. Acad. Sci. 108, 8172-8176.

Pétron, G., Frost, G., Miller, B.R., Hirsch, A.I., Montzka, S.A., Karion, A., Trainer, M., Sweeney, C., Andrews, A.E., Miller, L., 2012. Hydrocarbon emissions characterization in the Colorado Front Range: a pilot study. J. Geophys. Res. Atmos. 117.

Pezzagno, G., Maestri, L., 1997. The specificity of trans, trans-muconic acid as a biological indicator for low levels of environmental benzene. Indoor Built Environ. 6, 12-18.

Rahm, D., 2011. Regulating hydraulic fracturing in shale gas plays: the case of Texas. Energy Policy 39, 2974-2981.

Reading, C.L., Wien, F., 2009. Health Inequalities and the Social Determinants of Aboriginal peoples' Health ed`eds. National Collaborating Centre for Aboriginal Health Prince George, BC.

Scherer, G., Renner, T., Meger, M., 1998. Analysis and evaluation of trans, trans-muconic acid as a biomarker for benzene exposure. J. Chromatogr. B Biomed. Sci. Appl. 717, 179-199.

Schettgen, T., Musiol, A., Alt, A., Kraus, T., 2008. Fast determination of urinary S-phenylmercapturic acid (S-PMA) and S-benzylmercapturic acid (S-BMA) by columnswitching liquid chromatography-tandem mass spectrometry. J. Chromatogr. B 863, 283-292.

Slama, R., Thiebaugeorges, O., Goua, V., Aussel, L., Sacco, P., Bohet, A., Forhan, A., Ducot, B., Annesi-Maesano, I., Heinrich, J., 2009. Maternal personal exposure to airborne benzene and intrauterine growth. Environ. Health Perspect. 117, $1313-1321$. 
Tanner, J.P., Salemi, J.L., Stuart, A.L., Yu, H., Jordan, M.M., DuClos, C., Cavicchia, P., Correia, J.A., Watkins, S.M., Kirby, R.S., 2015. Associations between exposure to ambient benzene and PM2.5 during pregnancy and the risk of selected birth defects in offspring. Environ. Res. 142, 345-353.

Tsangari, X., Andrianou, X.D., Agapiou, A., Mochalski, P., Makris, K.C., 2017. Spatial characteristics of urinary BTEX concentrations in the general population. Chemosphere 173, 261-266.

Van Larebeke, N.A., Sasco, A.J., Brophy, J.T., Keith, M.M., Gilbertson, M., Watterson, A., 2008. Sex ratio changes as sentinel health events of endocrine disruption. Int. J. Occup. Environ. Health 14, 138-143.

Vengosh, A., Jackson, R.B., Warner, N., Darrah, T.H., Kondash, A.A., 2014. Critical review of the risks to water resources from unconventional shale gas development and hydraulic fracturing in the United States. Environ. Sci. Technol. 48, 8334-8348.

Verdina, A, Galati, R., Falasca, G., Ghittori, S., Imbriani, M., Tomei, F., Marcellini, L, Zijno, A., Vecchio, V.D., Crebelli, R., 2001. Metabolic polymorphisms and urinary biomarkers in subjects with low benzene exposure. J. Toxicol. Environ. Health A 64, 607-618.

Vinciguerra, T., Yao, S., Dadzie, J., Chittams, A., Deskins, T., Ehrman, S., Dickerson, R.R., 2015. Regional air quality impacts of hydraulic fracturing and shale natural gas activity: evidence from ambient VOC observations. Atmos. Environ. 110, 144-150.

Waidyanatha, S., Rothman, N., Fustinoni, S., Smith, M.T., Hayes, R.B., Bechtold, W., Dosemeci, M., Guilan, L., Yin, S., Rappaport, S.M., 2001. Urinary benzene as a biomarker of exposure among occupationally exposed and unexposed subjects.
Carcinogenesis 22, 279-286.

Wallace, L., 1990. Major sources of exposure to benzene and other volatile organic chemicals. Risk Anal. 10, 59-64.

Warner, N.R., Christie, C.A., Jackson, R.B., Vengosh, A., 2013. Impacts of shale gas wastewater disposal on water quality in western Pennsylvania. Environ. Sci. Technol. 47, 11849-11857.

White, H.L., 1992. Hazardous Waste Incineration and Minority Communities. Race and the Incidence of Environmental Hazards: A Time for Discourse. pp. 126-139.

Whitworth, K.W., Symanski, E., Coker, A.L., 2008. Childhood lymphohematopoietic cancer incidence and hazardous air pollutants in southeast Texas, 1995-2004. Environ. Health Perspect. 116, 1576.

Wilkins-haug, L., Gabow, P.A., 1991. Toluene abuse during pregnancy: obstetric complications and perinatal outcomes. Obstet. Gynecol. 77, 504-509.

Zahran, S., Weiler, S., Mielke, H.W., Pena, A.A., 2012. Maternal benzene exposure and low birth weight risk in the United States: a natural experiment in gasoline reformulation. Environ. Res. 112, 139-146.

Zhou, Y., Zhang, S., Li, Z., Zhu, J., Bi, Y., Bai, Y., Wang, H., 2014. Maternal benzene exposure during pregnancy and risk of childhood acute lymphoblastic leukemia: a meta-analysis of epidemiologic studies. PLoS One 9, e110466.

Zielinska, B., Fujita, E., Campbell, D., 2011. Monitoring of emissions from Barnett Shale natural gas production facilities for population exposure assessment. Desert Res. Inst. 71. 